\title{
MODELING THE GROWTH OF LAMBS IN THE EARLY STAGES OF POSTEMBRYONIC DEVELOPMENT
}

\author{
Natalia Nezhlukchenkoํㅜ, Anatolii Polevoi², Tetiana Nezhlukchenko³ \\ ${ }^{1}$ State Enterprise Research Farm "Askaniiske” of the Askaniiska State Agricultural Research Station of the Institute \\ of Irrigated Agriculture of the National Academy of Agrarian Sciences of Ukraine, 74862, Kherson region, \\ Kahovskyi district, village Tavrychanka, 40 rokiv Peremohy Str., Ukraine \\ 2 Odessa State Environmental University, 65016, 15 Lvivska Str., Odessa, Ukraine \\ ${ }^{3}$ Mykolayiv National Agrarian University, 54020, 9 George Gongadze Str., Mykolaiv, Ukraine
}

Link to this article: https://doi.org/10.11118/actaun.2021.026

Received: 10. 2. 2021, Accepted: 30. 3. 2021

To cite this article: NEZHLUKCHENKO NATALIA, POLEVOI ANATOLII, NEZHLUKCHENKO TETIANA. 2021. Modeling the Growth of Lambs in the Early Stages of Postembryonic Development. Acta Universitatis Agriculturae et Silviculturae Mendelianae Brunensis, 69(3): 311-318.

\begin{abstract}
Improving the efficiency of the sheep industry is based not only on additional investments, but also on the use of modern methods of breeding and selection. A significant role is given to modeling and forecasting processes in sheep breeding. The article is devoted to the development of a model for the growth and development of lambs in the first months of their post-embryonic period, which contains a system of equations describing the energy, protein and nutritional needs of animals. This model takes into account the influence of environmental factors on the growth and development of lambs and the features of the formation of future productivity.
\end{abstract}

Keywords: energy and protein requirements, growth and development, modeling, lamb, sheep

\section{INTRODUCTION}

Increasing animal productivity is directly based on the use of intensive factors, which include the achievements of genetics and biotechnology. This allows you to accelerate the pace of breeding processes in lines and populations (Mel'nyk et al., 2008; Annett et al., 2011; Wuliji et al., 2009; Wuliji et al., 2019). Selection improvement is based on the speed of digenesis, the accuracy of evaluating the genotype and predicting the productivity of animals in early ontogenesis (Raoul and Elsen, 2020; Chernobay and Huzenko, 2011). Whereas if the speed of digenesis is mainly based on the species characteristics and they can be accelerated by biotechnological techniques, then increasing the accuracy of the genotype assessment is the main way to improve selection methods (Shtompel and Bilous, 1997; Hansford et al., 2004). In our time, it is impossible to imagine a significant scientific research in animal husbandry, in which would not be used any methods of process modeling (Ibatulin, 2014; Kovalenko et al., 2010). In economic terms, the way of modeling growth processes and predicting live weight reduce the costs associated with raising and maintenance a large number of animals that in the future won't confirm high productivity level because of food costs. In order to reduce these costs, it is meant to be used the appropriate equations of the trajectories of growth and development of animals for modeling and predicting productivity.

In the individual development of lambs, the most important period is from birth to weaning from mothers. It is characterized by high growth rate of organs and body tissues that determine the external morphological and productive characteristics of the animal, as well as an intensive process of formation of the biomorphological status of the internal environment of the body, that determines its viability, adaptability and resistance to 
environmental factors (Kilchevskii, 1984; Turinskyi and Riabko, 2002; Bedhiaf-Romdhani et al., 2008).

The development of lambs after birth depends mainly on mother's milk and creep feeding. The influence of environmental factors under the conditions of stall maintenance is manifested through the regime of temperature and humidity, air illumination (Zhukorskyi, 2012; Nardone et al., 2010).

\section{MATERIALS AND METHODS}

When modeling the growth of lambs should proceed from the following premises:

- in the postembryonic period, the growth and development of the lambs are influenced by the characteristics of the breed, feeding and environmental conditions;

- lambs in the first 15-21 days live only on mother's milk, next there is a mixed feeding, and then feeding with concentrates and hay, the doses are increased from the first to the fourth month;

- at the age of 4.5 months lambs are weaned from the ewes;

- one of the main premises characterizing the peculiarities of the growth of lambs is their live weight (Kovalenko et al., 2010; Plokhinsky, 1969; Zishiri et al., 2014);

- the influence of air temperature in the shed on the formation of the heat balance of the body of lambs and their thermoregulation;

- it is taken into account that in good sunny weather in the afternoon from the age of 3 weeks lambs are let out to grass and heat balance of the body is formed under natural conditions of environmental factors;

- energy, protein and nutritional needs of animals are modeled.

The interaction of lambs with the environment both in stall and out at grass conditions is determined mainly by the thermoregulation of the body under the influence of environmental factors, the satisfaction of energy, protein and food needs.

In the first months of post-embryonic period, the lamb growth model is based on the system of equations, describing energy (Pomitun, 2008), protein and food needs of the animals (Khanin et al., 1978) and body heat balance formation (Yaroshevsky, 1968).

The main factors that determine food need include:

- energy needs due to radiation heat loss;

- energy needs associated with mechanical work (in the shed, out at grass);

- energy needs associated with maintaining the minimum functional activity of the most important organs and systems at rest;

- needs for substances necessary for the growth of the animal;

- needs for substances necessary for tissue integrity.

\section{RESULTS AND DISCUSSION}

\section{Energy Needs}

The energy needs of lambs are determined by the need to maintain a constant body temperature and radiation heat loss. It is established (Yaroshevsky, 1968), that physiological heat production is formed due to heat flux in the coat, radiation heat loss (effective radiation), a turbulent heat flux between the body surfaces and the surrounding air, heat consumption for evaporation from the body surface, heat consumption for evaporation from the surface of the respiratory system and heat consumption for heating exhaled air. The thermal power of an animal at rest (on an empty stomach) $W$ can be represented as (Khanin et al., 1978)

$W=W_{0}+W_{t}$,

wherein $W_{0}$ - the main exchange of the animal, that is represented by the equation

$W_{0}=\chi\left(P / P_{\max }\right) \times P^{3 / 4}$,

wherein $P$ - animal body weight; $P_{\max }$ - maximum weight of the animal.

Value $\chi\left(P / P_{\max }\right)$ represents species-specific function, that depends on the body weight

$\chi\left(P / P_{\max }\right)= \begin{cases}\left(0.75+1.25 P / P_{\mathrm{m}}\right) \chi_{0}, & P \leq 0.2 P_{\mathrm{m}}, \\ \chi_{0}, & P>0.2 P_{\mathrm{m}},\end{cases}$

wherein $\chi_{0}=70 \mathrm{kcal} / \mathrm{kg}^{0.75}$ day.

$W_{t}$-additional thermal power necessary to maintain a constant temperature of the body outside the thermoneutral zone, is represented as

$W_{t}= \begin{cases}W_{0} \frac{T_{c 1}-T_{e}}{T_{s}-T_{c 1}}, & T_{e}<T_{c 1}, \\ 0, & T_{e} \geq T_{c 1},\end{cases}$

wherein $T_{s}$-average body surface temperature of the animal; $T_{e}$ - environmental temperature; $T_{c 1}$ - lower boundary of the thermoneutral zone.

Equation (4) describes the additional thermal power spent on maintaining a constant body temperature of the lambs held in the shed.

At the beginning of grazing the value $W_{t}$ is determined characteristics of the heat balance of the animal's body (Yaroshevsky, 1968)

$W_{t}=T_{w}+E_{e f}+E_{t}+L E_{r}+L E_{s e}+F_{h}$,

wherein $T_{w}$ - heat flow in the wool; $E_{e f}$-radiation heat loss (effective radiation of the body); $E_{t}$ - turbulent heat flow; $L E_{r}$ - respiratory evaporation; $L E_{s e}$ - surface evaporation; $E_{h}$ - heating of the exhaled air.

The paper (Yaroshevsky, 1968) proposes the calculation of the components of the thermal balance of the body of animals. We consider the surface of the animal that is active in radiation, transpiration 
and heat transfer (Lakota, 2016; Belharfi et al., 2018; Khamiruev et al., 2018; Zeliatdinov et al., 2020).

The first type of active surface is rune surface that forms a "chamber" around the body of the animal, containing a significant amount of "buffer" air. The thermal condition of the rune surface is mainly determined by external factors - the amount of incoming radiant energy of the Sun, the amount of effective radiation, the intensity of turbulent exchange, and in cases where the rune surface is wet, - heat input for evaporation (Omarov and Skorikh, 2012). The rune surface heats during insolation and cools during the period of predominance of radiation. The thermal shocks occur during the day mostly on this surface.

The second type of active surface is the skin surface covered with wool. Unlike the rune surface, the thermal state of the skin surface is less variable, subject to regular fluctuations resulting from the vascular reactions of the body and significantly weakened by external factors. The heat exchange between the skin surface and the rune surface of an unshorn sheep can only occur through a layer of thick wool, the coat creates an obstacle to radiant fluxes and impedes the turbulent transfer of heat from the skin surface (Biltuev et al., 2017; Belik, 2011).

The third type of active surface is the skin surface, after cutting, having only a very thin and relatively rare hairline that does not interfere with radiation and turbulent heat transfer from the skin surface. The temperature is subject to significant fluctuations as a result of vascular reactions of the body and more intense heat exchange with the environment.

The heat fluxes in the coat of lambs and sheep are determined by two factors: the temperature gradient and the thermal conductivity of the wool in its natural state. The greater the difference in temperature between the rune surface and the skin surface, and the thinner the coat of wool, the greater the amount of heat gives off or receives the surface of the skin.

In summer nights the temperature of the rune surface differs little from the temperature of the surrounding air and is always much lower than the temperature of the skin surface. Under these conditions, the heat flux in the coat is directed from the surface of the skin to the rune surface. Heat is transferred to the environment (El Bouyahiaoui et al., 2018).

In the daytime the radiant energy absorbed by the active rune surface turns into thermal energy and raises the temperature of this surface to $60-70^{\circ}$. Under these conditions, the heat flux in the coat is directed from the heated rune surface to the surface of the skin and in total forms an exogenous load.

The calculation of the intensity of heat fluxes in the coat can be carried out using the equation

$T_{w}=\lambda \frac{\theta_{w}-\theta_{s}}{h} 60 \mathrm{kcal} / \mathrm{sm}^{2} \cdot \mathrm{min}$, wherein $T_{w}$ - heat flow in the wool; $\lambda$ - thermal conductivity of wool; $h$ - wool length; $\theta_{w}-$ wool temperature; $\theta_{s}$ - animal skin temperature.

Efficient radiation and turbulent heat transfer are important factors involved in the formation of the thermal state of the active surface.

Berliand M. Y. and Berliand T. H. (1961) established a theoretical dependence of the effective radiation in a cloudless sky on temperature and humidity (Berliand, 1956; Berliand and Berliand, 1961). This dependence can be represented as

$E_{e f}^{0}=k \sigma \theta^{4}(0.39-0.058 \sqrt{e})$,

wherein $E_{e f}^{0}$ - effective radiation value in a cloudless sky without taking into account the temperature difference between the active surface and air; $k$ - coefficient characterizing the deviation of the radiation of a given surface from the radiation of a black body; $\sigma$-Stefan-Boltzmann constant, equals $8.14 \cdot 10^{-11} ; \theta$ - air temperature; $e$ - absolute humidity in millimeters.

In addition to temperature and air humidity, the effective radiation is significantly affected by the temperature difference of the rune surface $\left(\theta_{w}\right)$ and air. In the presence of this difference, the effective radiation changes by $\left(k \sigma \theta_{\mathrm{w}}^{4}-k \sigma \theta^{4}\right)$ and for cloudless weather can be represented as

$E_{e f}=E_{a}^{0}+\left(k \sigma \theta_{\mathrm{w}}^{0}-k \sigma \theta^{4}\right)$.

To calculate the intensity of the turbulent heat flow, we use the equation of Budyko (1971), which is based on Newton's law on the relationship of heat transfer with the temperature difference of the surface of a heated (or cooled) body and air

$Q=\rho c_{p} D_{0-200}\left(\theta_{w}-\theta\right)$,

wherein $\rho$-Earth density, equals $0.0013 \mathrm{~g} / \mathrm{cm}^{3} ; c_{p}$ - air specific heat, equals $0.24 \mathrm{kcal} / \mathrm{g} \cdot \operatorname{degr} . ; D_{0-200}-$ integral characteristic of the conditions of vertical turbulent transfer between the active surface of animals and the atmosphere, called the coefficient of external diffusion; $\theta_{w}$ - temperature of the active surface of the animal.

The amount of water released during breathing (pulmonary evaporation) can be calculated by multiplying the difference in specific humidity of the exhaled and inhaled air $\Delta q$ by the mass of air passing through the respiratory organs per unit time

$E_{p}=\Delta q V_{m}$

Along with the removal from the body of the animal heat expended on evaporation from the surface of the respiratory organs, exhaled air removes the heat expended on its heating. The amount of this heat will be directly proportional to the mass of exhaled air and inversely proportional to the temperature of the inhaled air. 
The amount of heat spent on heating the exhaled air per unit time can be found by multiplying the difference in the temperature of the exhaled and inhaled air $\Delta \theta$ by the specific (weight) heat capacity of air $c_{p}$ and the mass of exhaled air $V_{m}$.

In order to maintain a constant body temperature, the animal needs, in addition to providing basic metabolism, energy for performing mechanical work associated with movement, increasing the calorie content of the body and releasing the substance lost in the process of digestion. In addition, during the processes of digestion, absorption and assimilation of food, additional energy is released, which is manifested in the calorigenic effect of food.

From the full power of $W_{M}$ consumed by the animal's body, only a part, proportional to the muscle efficiency $\eta$, is converted into mechanical power $W_{\text {men }}(1-\eta) / \eta$. The rest of the heat power is released in the body in the form of heat and in the process of heat transfer through the surface of the body enters the environment.

The volume, percentage of the diet and the digestibility of its individual components determine the caloric effect of food (Chernavskii and Chernavskaiia, 1973). The heat capacity associated with the caloric effect of food $W$ is defined as the proportion of the main metabolism

$W_{c}=k_{W} W_{0}$,

wherein $k_{W}$-a parameter characterizing the share of the main metabolism falling within additional energy release associated with the calorigenic effect of food.

Equation (4) describes the power necessary to maintain a constant body temperature of the animal in the absence of physical activity and food. When mechanical work is performed by animals (lambs move around in the shed and out at grass), as well as due to food intake, when the calorigenic effect occurs, the thermal power necessary to maintain the body temperature of the animal will decrease

$W_{t}^{*}=\left\{\begin{aligned} & W_{t}-\left(W_{c}+W_{\text {meh }} \frac{1-\eta}{\eta}\right) ; W_{t}>W_{c}+W_{\text {meh }} \frac{1-\eta}{\eta}, \\ & 0 \quad ; \quad W_{t} \leq W_{c}+W_{\text {meh }} \frac{1-\eta}{\eta} .\end{aligned}\right.$

The change in calorie content of the animal's body that occurs when the body weight changes, requires additional energy consumption. The additional power necessary to change the calorie content of the body is determined by the equation:

$W_{K}=\frac{d\left(C_{b} P\right)}{d t}$,

wherein $C_{b}$ - average energy density of the body.

Additional energy consumption of the animal's body is also associated with the release of substances lost in the process of digestion (excrement, methane). The thermal power that the body spends on the release of substances is determined by the equation:

$W_{e}=\frac{d\left(C_{e} P_{e x}\right)}{d t}+\frac{d\left(C_{s} P_{s}\right)}{d t}$,

wherein $P_{\mathrm{ex}}, P_{s}$ - mass of substances that are excreted by the animal in the process of digestion and streamlined synthesis, respectively; $C_{e}, C_{s}$ - caloric content of substances released by the body in the process of digestion and streamlined synthesis, respectively.

Thus, the total energy consumption of the animal's body $\mathrm{W}_{\Sigma}$ can be written as follows

$W_{\Sigma}=W_{0}+W_{c}+W_{t}^{*}+\frac{W_{\text {meh }}}{\eta}+\frac{d\left(C_{b} P\right)}{d t}+\frac{d\left(C_{e} P_{e x}\right)}{d t}+\frac{d\left(C_{s} P_{s}\right)}{d t}$.

The total amount of energy $W_{\mathrm{y}}$ digested per unit time will be equal to

$W_{y}=W_{\Sigma}-\frac{d\left(C_{e} P_{e x}\right)}{d t}$.

Accordingly digested energy can be written as follows

$W_{y}=W_{0}+W_{c}+W_{t}^{*}+\frac{W_{m e h}}{\eta}+\frac{d\left(C_{b} P\right)}{d t}+\frac{d\left(C_{s} P_{s}\right)}{d t}$.

Based on the equation (17), the needs of the body in the digestible energy $W_{\mathrm{v}}$ necessary to satisfy all types of energy needs can be calculated (4).

\section{Protein Needs}

In the first weeks of life, lambs eat mother's milk and food requirements will be determined by protein balance. There are protein needs associated with the need to restore protein compounds and those associated with the synthesis of new tissues (animal growth):

$B=B_{M}+B_{g}+B_{s}$,

wherein $B$-necessary amount of digested protein per unit time; $B_{M}$ - necessary amount of digested protein per unit time to restore body tissues; $B_{g}$ - the amount of digested protein consumed by the animal per unit time for the synthesis of new tissues during growth; $B_{s}$ - the amount of digested protein consumed by the animal per unit time for the synthesis of a proteincontaining substance secreted by the body.

According to (Chernavskii and Chernavskaiia, 1973) regenerative protein needs (maintenance costs) are proportional to the basal metabolism

$B_{M}=\frac{1}{\kappa} \gamma_{0} \chi\left(\frac{P}{P_{m}}\right) P^{3 / 4}$, 
wherein $\kappa$-biological value of protein; $\gamma_{0}=15 \cdot 10^{-6} \mathrm{~kg}$ protein/kcal.

The amount of protein spent per unit of time on the synthesis of new tissues is proportional to the growth rate of the protein component

$B_{g}=\left(1+\alpha \frac{\dot{P}_{B}}{\beta_{b} P}\right) \frac{\dot{P}_{B}}{\kappa}$,

wherein $a$ - parameter dependent on the age of the animal; $\dot{P}_{B}-$ protein component growth rate; $\beta_{b}$ - average weight concentration of proteins in the body.

Thus, the total need of the animal in the digested protein per unit of time (4) is determined by the equation

$B=\frac{1}{\kappa}\left\{\gamma_{0} \chi \frac{P}{P_{m}} P^{0.75}+\left[1+\alpha \frac{d\left(\beta_{b} P+\beta_{s} P_{s}\right)}{\beta_{b} P d t}\right] \frac{d\left(\beta_{b} P+\beta_{s} P_{s}\right)}{d t}\right\}$.

\section{Food Requirement}

In most situations, food requirements are determined by energy and protein consumption. The minimum food intake (Khanin et al., 1978) is the minimum amount of food that the animal consumes per unit of time and necessary to cover the corresponding type of costs. The minimum food intake necessary to meet the protein needs of the animal is determined by the equation

$\Pi_{B}=\frac{B}{d_{b} b}$,

wherein $B$-the amount of digested proteins required by the animal's body per unit time; $d_{b}$ - protein digestion coefficient; $b$ - weight concentration of proteins in food.

Based on equations (21-22) it can be written as

$\Pi_{B}=$

$=\frac{a_{g}}{d_{b} b \kappa}\left\{\gamma_{0} \chi \frac{P}{P_{m}} P^{0.75}+\left[1+a \frac{d_{b}\left(\beta_{b} P+\beta_{s} P_{s}\right)}{\beta_{b} P d t}\right] \frac{d_{b}\left(\beta_{b} P+\beta_{s} P_{s}\right)}{d t}\right\}$,

wherein $a_{g}$ - specific function of self-sufficiency.

This function characterizes the ratio of the amount of food assimilated with mother's milk to minimum needs

$a_{g}=-5 \cdot 10^{-7} n^{3}+0.0001 n^{2}-0.0195 n+1.0083$,

wherein $n$ - number of days from birth.

The minimum food intake $\Pi_{g}$ necessary to meet the energy needs of the animal's body is determined by the equation

$\Pi_{W}=\frac{W_{y}}{C}$, wherein $C$ - average specific effective caloric value of food, that takes into account losses in the process of assimilation of food associated with the release of substances of energy value. It is believed that the value $C$ is less than the average specific effective caloric value of food.

According to the equation (17) the minimum food intake due to energy consumption can be represented as

$\Pi_{W}=\frac{1-a_{g}}{C}\left\{W_{0}+W_{c}+W_{t}^{*}+\frac{W_{\text {meh }}}{\eta}+\frac{d\left(C_{b} P\right)}{d t}+\frac{d\left(C_{s} P_{s}\right)}{d t}\right\}$.

In equation (26), the power spent on maintaining the body temperature outside the thermoneutral zone can take two values:

1) $W_{t}^{*}=W_{t}-\left(W_{c}+\zeta \Pi_{W}^{1} \frac{1-\eta}{\eta}\right) ; W_{t}>\left(W_{c}+\zeta \Pi_{W}^{1} \frac{1-\eta}{\eta}\right),(27)$

2) $W_{t}^{*}=0 ; \quad W_{t} \leq\left(W_{c}+\zeta \Pi_{W}^{2} \frac{1-\eta}{\eta}\right)$.

In the second case, all energy requirements due to maintaining the body temperature outside the thermoneutral zone are covered due to the calorigenic effect and heat losses that occur during mechanical work in the process of obtaining food.

Using relations (27) and (28), we represent equation (26) for the cases considered as follows:

$\Pi_{W}^{1}=\frac{1}{C-\zeta}\left[W_{0}+W_{t}+\frac{d\left(C_{b} P\right)}{d t}+\frac{d\left(C_{s} P_{s}\right)}{d t}\right]$,

$\Pi_{W}^{2}=\frac{1}{C-\frac{\zeta}{n}}\left[W_{0}+W_{c}+\frac{d\left(C_{b} P\right)}{d t}+\frac{d\left(C_{s} P_{s}\right)}{d t}\right]$

Or more compact

$\Pi_{W}=\max \left\{\Pi_{W}^{1}, \Pi_{W}^{2}\right\}$.

Equations (26) and (29)-(31) allow us to find the dependence on the age of the amount of food $\Pi_{B}(\mathrm{t})$ and $\Pi_{W}(\mathrm{t})$ required by the body per unit time to satisfy protein and energy needs.

Depending on the conditions, protein or energy requirements determine the amount of food needed. Since protein needs are especially large during the growth period, it is natural to assume that in this period the factor limiting food intake is protein requirement. In the future, as the relative growth rate decreases, protein requirements for food decrease, and energy becomes a factor limiting food intake. Therefore, a species-specific value can be introduced that determines the age $\tau_{B}$ at which energy requirements begin to limit food intake. For lambs, this age comes when weaning from the mother at the age of about 135-140 days. 
Accordingly, the minimum food requirements can be written as

$\Pi=\max \left\{\Pi_{B}, \Pi_{W}\right\}$.

The mechanical power developed by the animal is associated with its movement. For an adult, the movement is mainly due to the need to get food and, therefore, the value of mechanical power on the right side of equation (26) will be a function of the minimum food intake, which is described by the following equation

$W_{m e h}=\zeta \Pi_{g}$,

wherein $\zeta$ - power factor, i.e. mechanical work spent on obtaining a unit of food; $\Pi_{g}$ - the amount of food obtained by the animal per unit of time.

The relationship between the amount of food obtained during the time $\Delta t$ is determined by the distance $l$ that the individuals need to walk during this time and the food density $y$, i.e. mass of available food per unit area. This relations is described as

$\Pi_{g}=v y \frac{l}{\Delta t}$,

wherein $v$ - species-specific constant that has the meaning of the effective feed capture width and takes into account the geometric dimensions of the animal and the degree of use of the feed base.

The effective feed capture width is proportional to the linear dimensions of the body and is related to body weight by the relation

$v=a_{v} P^{1 / 3}$,

wherein $a_{v}$ - allometric feed efficiency coefficient.

Equation (34) allows you express so-called mobility of animals in terms of the amount of food obtained per unit time and the density of feed. By mobility we mean the average distance of a sufficiently large period of time, related to the magnitude of this period. Mobility has the dimension of speed.

The mobility of animals is mainly due to the need for food. Based on (34), as a first approximation, we can write

$\mathrm{v}=\frac{\Pi_{g}}{v y}$,

wherein $v$ - mobility.

Assuming that all the mechanical power developed by the animal is spent on movement when searching for and obtaining food, using the energy coefficient of nutrition $\zeta$, we can write (Khanin et al., 1978).

$W_{\text {meh }}=a_{v} P v=\zeta \Pi_{g}$,

wherein $\alpha_{v}$ - species-specific constant equal to the cost of mechanical power per unit mass of the body of an animal moving at a unit rate.
From equations (36) and (37) we find an approximate expression for $\zeta$

$\zeta=\frac{\alpha_{v} P}{v y}$,

The amount of food produced by the lamb in the first months of life is determined by the amount of the feeding $\left(\Pi_{f}\right)$ that gradually increases from birth to the period of weaning from the mother from $50 \mathrm{~g}$ to $250 \mathrm{~g}$ (Stapai et al., 2013). It can be written as

$\Pi_{f}=0.0043 n^{2}+1.7027 n-7.5758$.

In addition, the lamb, starting from the age of two months, moves with adults, gets its own food. Thus, the amount of food obtained during the time $\Delta t$ will be equal to the sum of the amount of fertilizing and the amount of food obtained during grazing when moving with adults $\left(\Pi_{m}\right)$, is calculated as per the equation

$\Pi_{g}=\Pi_{f}+\Pi_{m}$.

The amount of food obtained during the grazing by the lamb, we find by the expression equation

$\Pi_{m}=v y l \frac{\tau_{t m}}{24}$.

In the period from birth to weaning from mothers, the mechanical power developed by the body of the lamb is the sum of the costs of moving in a cat's night, moving to a feeder, and the cost of moving in the shed $W_{\text {sh }}$ and getting food together with adults on a pasture $W_{m}$

$W_{\text {meh }}=W_{s h}+W_{m}$.

When moving in the shed, the mechanical power developed by the lamb consists of the power spent on moving around the shed and the power spent on moving to the feeder

$W_{s h}=\frac{d_{v} P}{l_{s t}}\left(l_{s h}+l_{f}\right) \eta$,

wherein $d_{v}$ - the magnitude of the vertical displacement of the center of gravity of the body at one step; $l_{s h}$ - the distance travelled by a lamb in the shed per day; $l_{f}$ - distance passed by lamb in a farm for a day; $l_{\text {st }}$ - step length; $\eta$ - muscle efficiency.

When moving and obtaining food, the mechanical power expended by the lamb

$W_{m}=\alpha_{v} P v \frac{\tau_{t m}}{24}$,

wherein $\tau_{t m}$ - grazing time, which is calculated by the equation

$\tau_{t m}=0.06 j$,

wherein $j$ - the age from birth, day. 
When modeling the dynamics of the mass of an animal, two situations are considered (Khanin et al., 1978).

The first corresponds to a situation in which additional heat generation is necessary to maintain a constant body temperature, i.e.

$W_{t}>W_{c}+\frac{1-\eta}{\eta}\left[\zeta\left(\alpha_{g} \Pi_{1}\right)+W_{m}\right]$

follows from (27) and (28), and therefore, the growth rate is determined by the equation

$\frac{d P}{d t}=\frac{1}{C_{b}}\left[\Pi\left(C-\alpha_{g} \zeta\right)\right]-W_{0}-W_{t}-W_{m}-\frac{d\left(C_{s} P_{s}\right)}{d t}$.
It is assumed that the specific calorie content of the body does not depend on time.

The second situation corresponds to the case when the additional thermal power necessary to maintain a constant body temperature is covered by the heat released in the muscles during mechanical work

$W_{t}<W_{c}+\frac{1-\eta}{\eta}\left[\zeta\left(\alpha_{g} \Pi_{2}\right)+W_{m}\right]$

And then the growth rate takes the form

$\frac{d P}{d t}=\frac{1}{C_{b}}\left[\Pi\left(C-\frac{\alpha_{g} \zeta}{\eta}\right)-W_{0}-W_{c}-\frac{W_{m}}{\eta}-\frac{d\left(C_{s} P_{s}\right)}{d t}\right]$.

\section{CONCLUSION}

Individual growth of animals in the postnatal period of ontogenesis is a continuation of a gradual increase in live weight, which began in the embryonic state. It occurs naturally and corresponds to the genetic programs that are inherent in each biological species. In fact, the basic parameters for the study and calculations are the initial and final live mass of individual individuals. These indicators are closely related to other intermediate growth values.

In theoretical calculations, the characteristic features of the growth and development of young sheep from birth to the formation of productive qualities were determined.

Based on the experimental principles in the biology and physiology of animals (Khanin et al., 1978), as well as the laws governing the formation of their heat balance (Yaroshevsky, 1968), a model is proposed for the influence of environmental factors on the growth and development of lambs in the first months of the post-embryonic period and the formation of their future productivity. The use of this development in the advanced sheep breeding farms of the south of Ukraine has shown the feasibility and economic efficiency of its practical application.

\section{REFERENCES}

ANNETT, R. W., CARSON, A. F., DAWSON, L. E. R., IRWIN, D. and KILPATRICK, D. J. 2011. Effects of breed and age on the performance of crossbred hill ewes sourced from Scottish Blackface dams. Animal, 5(3): 356-366.

BEDHIAF-ROMDHANI, S., DJEMALI, M. and BELLO, A. A. 2008. "Inventaire des différents écotypes de la race Barbarine en Tunisie”. Animal Genetic Resources Information, 43: 43-47.

BELHARFI, F. Z., DJAOUT, A., AMEUR AMEUR, A., SAHRAOUI, H. and GAOUAR, S. B. S. 2018. A comparative study of wool quality in sheep breeds in western Algeria. Genetics and Biodiversity Journal, 2(1): 19-25.

BELIK, N. I. 2011. The relationship of the characteristics of bright with different shades of wool. Bulletin of the Stavropol agro-industrial complex, 4(4): 22-24.

BERLIAND, M. Y. 1956. Prediction and regulation of the thermal regime of the surface layer of the atmosphere. Hidrometeoizdat.

BERLIAND, M. Y. and BERLIAND, T. H. 1961. Determination of the effective radiation of the Earth, taking into account the influence of cloudiness. Journal USSR Academy of Sciences, 1: 43-54.

BILTUEV, S. I., ZHILJAKOVA, G. M. and OCHIROVA, E. V. 2017. Some physical and mechanical properties of wool sheep of Burat type of transbaikal breed depending on the tone. Journal of the Buryat State Agricultural Academy named after V. R. Filippov, 4(49): 31-39.

BUDYKO, M. I. 1971. Climate and life. Hidrometeoizdat.

CHERNAVSKII, D. S. and CHERNAVSKAIIA, N. M. 1973. Problems of abiogenesis. Theoretical and Experimental Biophysics, 4: 3-38.

CHERNOBAY, E. N. and HUZENKO, V. Y. 2011. Wool productivity of fine fleece bright different genotypes. Zootekhnyya, 8: 23-24.

EL BOUYAHIAOUI, R., BELKHEIR, B., BELKHEIR BEN AHMED, N., MOULLA, F., BENSALEM, M., ARBOUCHE, F. and GHOZLANE, F. 2018. Etude des caractéristiques de laines d'ovins Tazegzawt. Livestock Research for Rural Development, 30: 83. 
HANSFORD, K. J., VAN VLECK, L. D. and SNOWDER, G. D. 2004. Estimates of genetic parameters and genetic changes for reproduction, weight, and wool characteristics of Rambouillet sheep. Small Ruminant Research, 57(2-3): 175-186.

IBATULIN, I. I. 2014. Sheep breeding Ukraine in light of trends in world development. Effective livestock, 2: 12-13.

KHAMIRUEV, T. N., VOLKOV, I. V. and BAAZARON, B. Z. 2018. Productive qualities of local semi-coarsehaired sheep. Siberian Bulletin of Agricultural Science, 48(4): 72-79.

KHANIN, M. A., DORFMAN, H. L., BUKHAROV, I. B. and LEVADNYI, V. H. 1978. Extreme principles in biology and physiology. Nauka.

KILCHEVSKII, A. V. 1984. Assessment of the general and specific adaptive ability of genotypes. In: Abstracts of the II All-Union Conference, pp. 44-45.

KOVALENKO, V. P., KHALAK, V. I., NEZHLUKCHENKO, T. I. and PAPAKINA, N. S. 2010. Biometric analysis of variability of signs of farm animals and poultry. Textbook on farm animal genetics.

LAKOTA, Y. A. 2016. Wool productivity of crossbreeds of the I generation from crossing of the Stavropol ewes of various tonnage of wool with rams producers of breed Manychsky merino of the EM-214 wool line. International scientific journal "Symbol of Science", 1: 45-47.

MEL'NYK, J. F., KOVALENKO, V. P., UGNIVENKO, A. M. and NAJDENKO, K. A. 2008. Selection of farm animals. Kiev.

NARDONE, A., RONCHI, B., LACETERA, N., RANIERI, M. S. and BERNABUCCI, U. 2010. Effects of climate changes on animal production and sustainability of livestock systems. Livestock Science, 130(1-3): 57-69.

OMAROV, A. A. and SKORIKH, L. N. 2012. Efficiency of fine-wool and crossbred sheep with various fineness wool. Sheep, goats, wool, 1: 21-23.

PLOKHINSKY, N. A. 1969. Guide to biometrics for livestock specialists. Moscow.

POMITUN, I. A. 2008. Peculiarities of sexual activity and sexual behavior of young sheep of Kharkiv intrabreed type of Prekos breed, depending on different energy concentration in diets. Modern methods of agricultural reproduction of animals: Status and prospects of development, 96: 341-346.

RAOUL, J. and ELSEN, J-M. 2020. Effect of the rate of artificial insemination and paternity knowledge on the genetic gain for French meat sheep breeding programs. Livestock Science, 232: no pagination.

STAPAI, P. V., PARANIAK, N. M. and TKACHUK, V. M. 2013. Physico-chemical properties of wool and fat of ewes under conditions of use in diets of different levels of iodine. Bulletin of Agrarian Science of the Black Sea Coast, 4(76): 150-154.

SHTOMPEL, M. V. and BILOUS, O. V. 1997. Environment and breeding value. Selection: scientific-production bulletin, 4: 163-168.

TURINSKYI, V. M. and RIABKO, V. M. 2002. Directions of harmonization of sheep breeding with the natural environment of the southern steppes of Ukraine. Bulletin of Dnipro State Agrarian University, 2: 119-121.

WULIJI, T., GLIMP, H. and FILBIN, T. 2009. Introduction of Merino genetics to improve Western range sheep flock wool quality and wool clip profits. In: Proceedings of US Sheep Research Programs, American Sheep Industry Association Convention. San Diego, pp. 47-49.

WULIJI, T., WURI, L., GLIMP, H. and FILBIN, T. 2019. Merino Breeding Program Improves Wool Quality in US Wool Sheep Flocks. Universitätsverlag Göttingen.

YAROSHEVSKY, V. A. 1968. Weather and fine-wool sheep breeding. Leningrad.

ZELIATDINOV, V. V., ORESHNIKOVA, S. M., YUKHMANOVA, N. A. and DAVYDENKOVA, V. P. 2020. Objective methods for determining the tonality of wool. Sheep, goats, wool, 1: 29-31.

ZHUKORSKYI, O. M. 2012. Weather-climatic and technological factors of keeping beef cattle: monograph. Agricultural science.

ZISHIRI, O. T., CLOETE, S. W. P., OLIVIER, J. J. and DZAMA, K. 2014. Genetic parameters for live weight traits in South African terminal sire sheep breeds. Small Ruminant Research, 116(2-3): 118-125.

Contact information

Natalia Nezhlukchenko: nataly12154@gmail.com (corresponding author)

Anatolii Polevoi: apolevoy@te.net.ua

Tetiana Nezhlukchenko: tekhnolohiivpt@gmail.com 